\title{
Frequency of Hypertension after 10 Years of Military Services in Bangladesh Army
}

\author{
H. M. Khaleduzzaman and Nafisa Jabin Mishu
}

\section{ABSTRACT}

\begin{abstract}
Bangladesh army performs different activities in war and peace in all terrain so physical fitness is the prime requirement for military services. Though military personnel perform regular physical activities they are not immune from hypertension. Hypertension is a multivariate disease ranging from physical and psychological factors. In this study hypertension found among $16 \%$ of participants where some modifiable factors were found associated with development of early onset hypertension like lack of physical activities, increase mental stress, overweight, smoking, pattern of dietary habit, lack of awareness and abnormalities in lipid profile. Further study is required to establish these modifiable risk factors and their intervention to prevent early onset hypertension among military service personnel in Bangladesh. Which not only improve the health condition of military personnel but also increase the efficiency of Bangladesh Army as well as it will reduce the health expenditure related to hypertension.
\end{abstract}

Keywords: Military service, Hypertension, frequency, modifiable risk factors, mental stress.

\section{INTRODUCTION}

Military service is a service by an individual or group in an army. Army has diverse of activities during peace and war. Bangladesh Army consists of young healthy Bangladeshi soldiers. They came from different socio-economic status. They vary in their social, cultural, and educational background as well as the existing rank structure. Military persons perform difficult activities including constructions in the country and control the terrorism both hill and land area. They also perform operational activities in war situation under Unitated Nations (UN) in mission. To perform complex task effectively physical fitness is the prime requirement for military service. Hypertension is a common phenomenon among general population, but it is not usual among military persons. No hypertensive individual is allowed to join in services though it is observed that hypertension is found in early age among military persons. Hypertensions not only increase the risk of early onset ischemic heart disease and stroke but also reduce the efficacy of military personnel. Moreover, some of the military personnel had to go to premature retirement from the services due to hypertension and its complications which ultimately influences on society. Hypertension is a common condition. Hypertension in developing world is high which may be due to less availability and affordability of necessary antihypertensive drugs as required as that in developed countries. [1] Central obesity is strong risk factors of high prevalence of hypertension among Indian immigrants to Britain. [2] But little is known about its frequency in the Bangladesh Army.
Early hypertension among the combatants not only reduces the efficiency but also largely increases the health expenditure and health burden. This study will open an area of further research and appropriate action regarding early detection and prevention of long-term complications among military service personnel.

\section{MATERIALS AND METHODS}

This was a cross-sectional study which was carried out over a sample of 245 military personnel after 10 years of services but below 40 years of age in Bangladesh Army. The study was done at Combined Military Hospital-Dhaka during six month period, beginning July 2019 to December 2019, without interruption. Blood pressure was measured with an aneroid sphygmomanometer. Two measurements of the blood pressure were taken on the right arm in sitting position relaxed for 5 minutes and at least 30 minutes after they had last smoked, exercised, or ingested caffeine. The mean of the measures was used. The cut-off points for hypertension were $\geq 140 \mathrm{mmHg}$ for systolic pressure and $\geq 90 \mathrm{mmHg}$ for diastolic pressure or who had reported taking medicine for high blood pressure. The study variables were included risk factors for hypertension. Data were collected by purposive Simple random sampling method with a structured questionnaire. Finally, data analysis was done using SPSS25.

Military persons who served 10 years in Bangladesh Army and those who have given informed consent were included in this study. One the other hand who was suffering from 
chronic kidney disease, thyroid disorder, Phaeochromocytoma, renal artery stenosis was excluded from this study. Participants who were taking steroid chronically due to any reason, who were unwilling to give informed consent and age over 40 years were out of this study.

\section{RESULT}

The prevalence of hypertension varies from country to country. It also varies from community to community within the country [1]-[5]. But little is known about Bangladeshi military personnel regarding hypertension, in this study we will highlight frequency of hypertension after 10 years of military services in Bangladesh Army among age group bellow 40 years of age.

Hypertension was found among $16.3 \%$ military service members who met inclusion criteria in this study (Fig. 1). Most of the participants were Sargent, corporal, lance corporal and sainik. 95\% participants were married. Majority of the participants' age group were 30-39 years (Fig. 5). There is a strong association (72.5\%) between hypertensive and smoking (Fig. 2). 84\% of participants have lack of knowledge regarding hypertension and its complication. $22.5 \%$ of hypertensive participants were overweight (Fig. 3). There were very few hypertensive participants were suffering from hyperthyroidism and hypothyroidism $1.2 \%$ and $0.8 \%$ respectively.

Hypertension runs in family $35 \%$ of cases (Fig. 6). Frequency of hypertension found lower who take part in daily exercise >one hour (Fig. 4). Most of the hypertensive individuals were taking their meal from barrack. Already 5\% of hypertensive participants developed arterio-venous nipping and $2.5 \%$ developed silver wiring (Fig. 8), left ventricular hypertrophy was found among $10 \%$ of hypertensive participants (Fig. 9). Raised low density lipoprotein was found among $42.5 \%$ and raised triglyceride was found among $60 \%$ of hypertensive participants (Fig. 10 and Fig. 11, respectively). Majority of participants were mentally okay $(80 \%)$ but $16 \%$ were frustrated and only $4 \%$ were suffering from botheration in their unit activities. Frequency of hypertension increases with increased level of mental stress among the participants (Fig. 7).

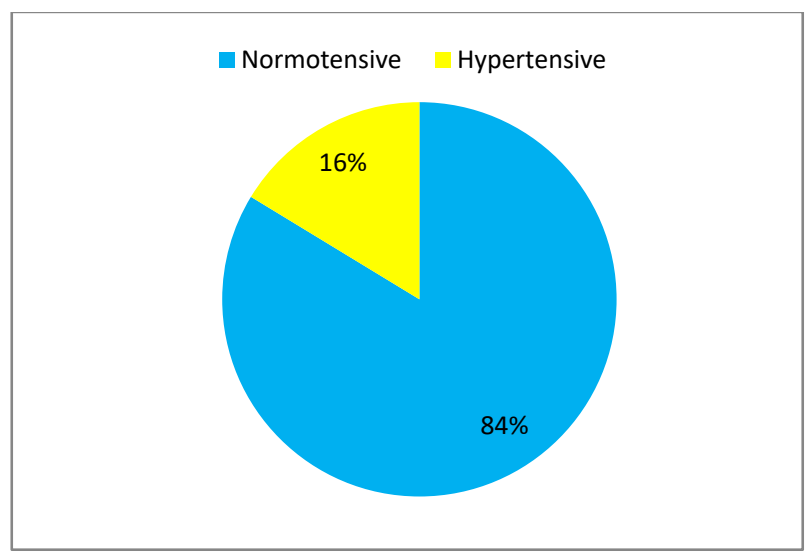

Fig. 1. Frequency of hypertension among the respondents $(n=245)$.

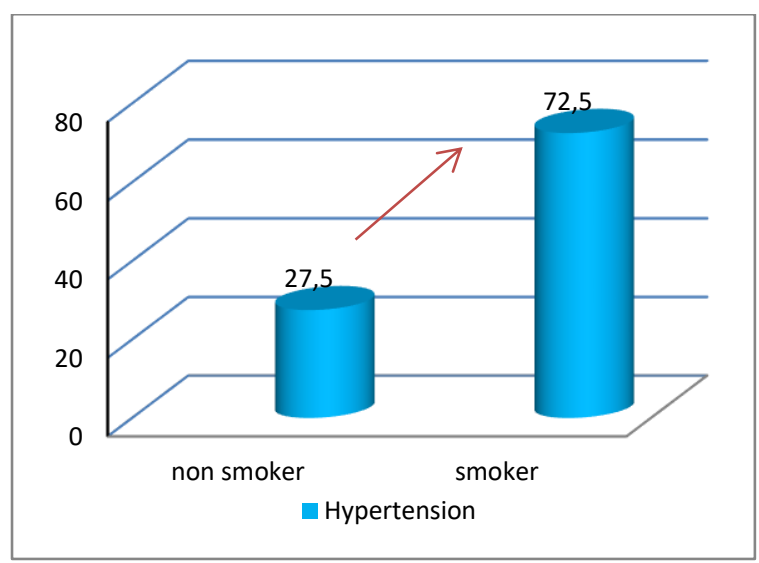

Fig. 2. Distribution of hypertensive respondents by smoking $(n=40)$.

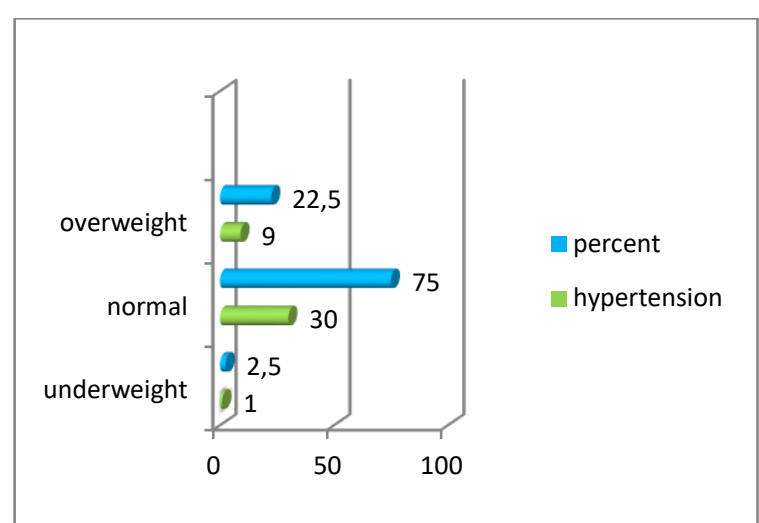

Fig. 3. Distribution of hypertensive respondents by BMI $(n=40)$.

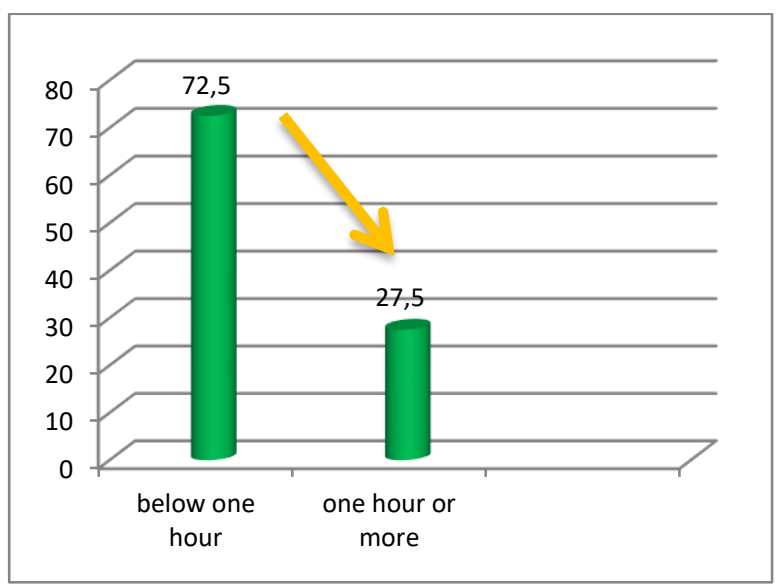

Fig. 4. Distribution of hypertensive respondents by daily physical exercise $(n=40)$.

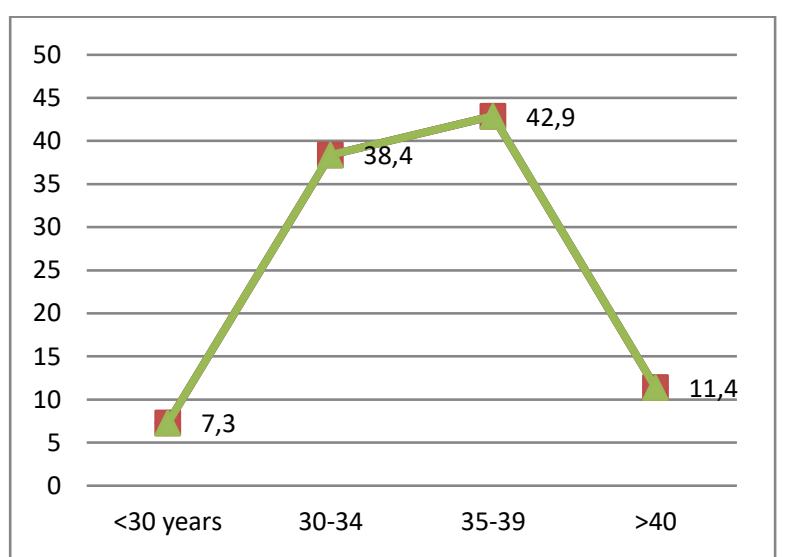

Fig. 5. Distribution of the participants by age group $(n=245)$. 


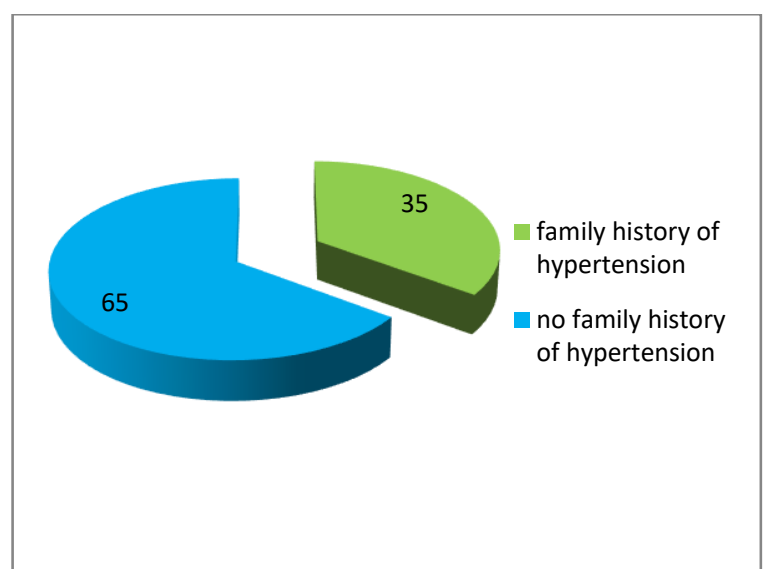

Fig. 6. Distribution of hypertensive respondents by family history of hypertension $(n=40)$.

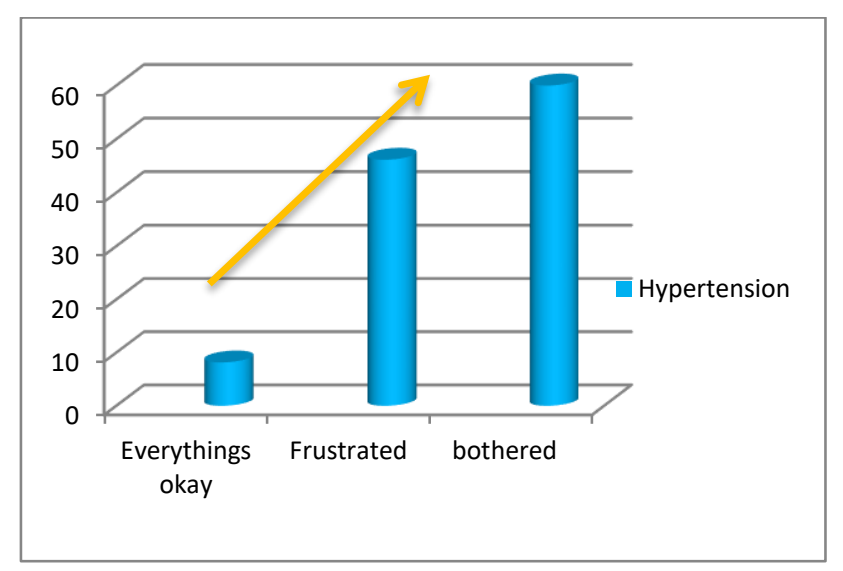

Fig. 7. Distribution of hypertensive respondents by mental stress $(n=40)$.

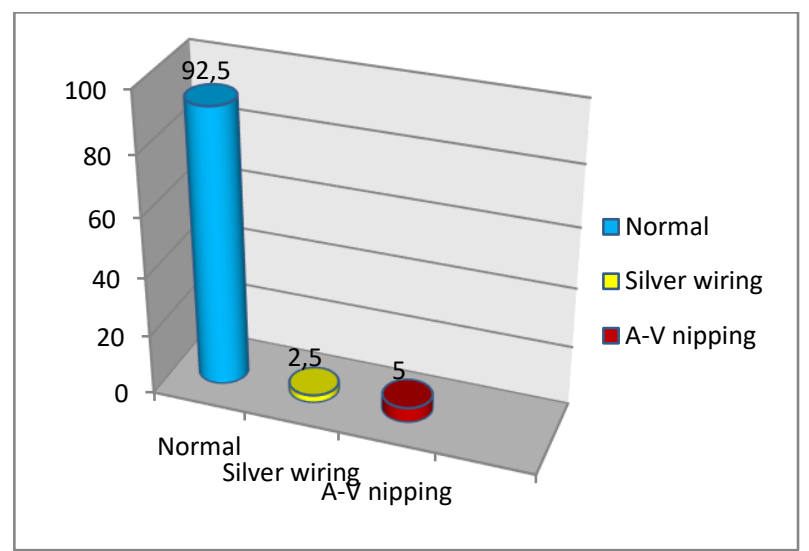

Fig. 8. Distribution of hypertensive respondents by changes in fundus $(n=40)$.

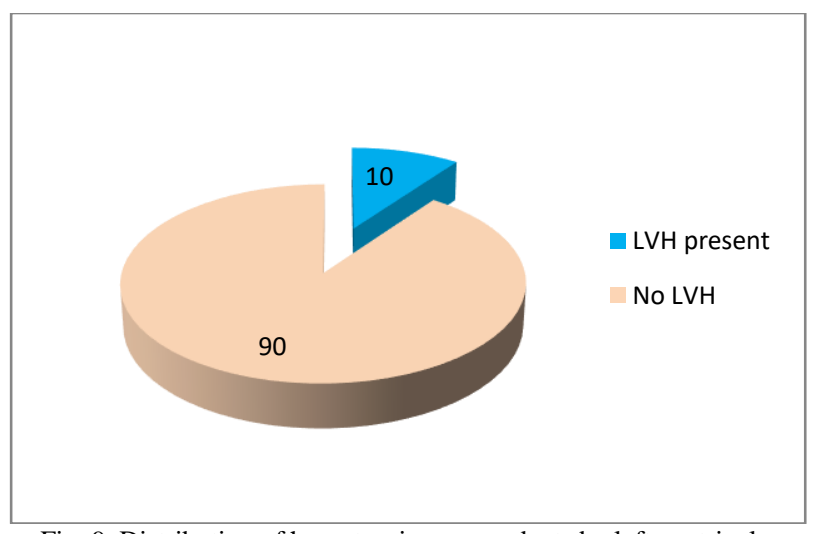

Fig. 9. Distribution of hypertensive respondents by left ventricular hypertrophy $(n=40)$.

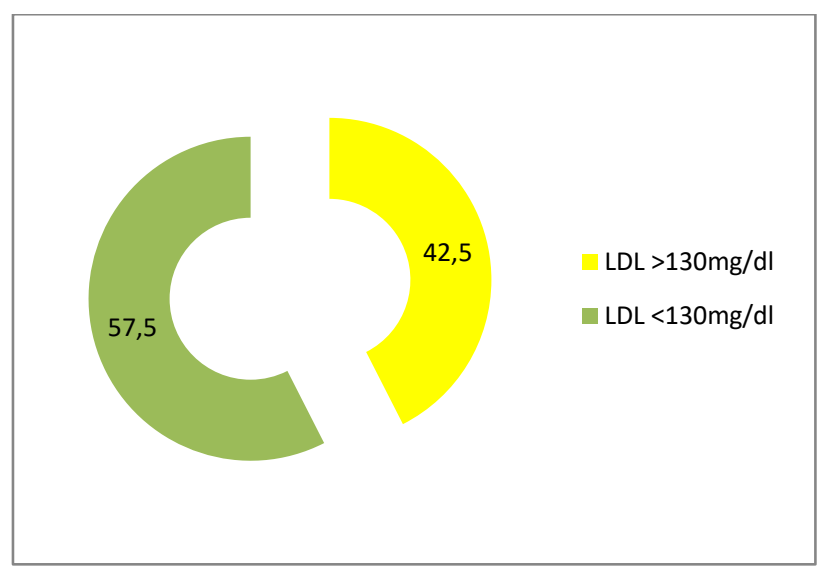

Fig. 10. Distribution of hypertensive respondents by LDL level $(n=40)$.

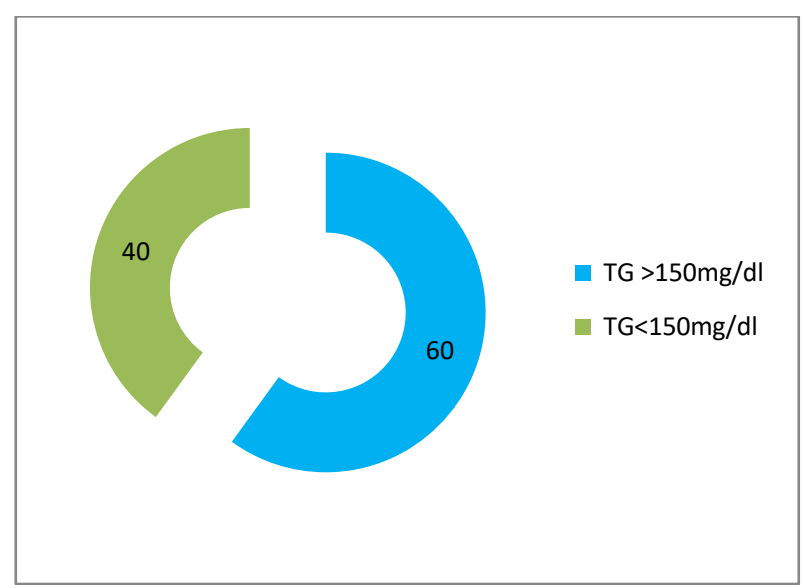

Fig. 11. Distribution of hypertensive respondents by Triglyceride level $(n=40)$.

\section{DISCUSSION}

In this study the frequency of hypertension was $16.3 \%$ after 10 years of military service in Bangladesh Army. This correlates with other study conducted by Hemma in Pakistan, she found prevalence of hypertension $17.5 \%$ among male and $14 \%$ among female. [6] Higher prevalence of hypertension was found among male $21.86 \%$ and female $19.8 \%$ in Wardha, [7] and 23\% in Philippines. [8] In 1996 The WHO reported that 20\% populations were hypertensive. [9] In United States higher prevalence of hypertension $33.5 \%$ found among nonHispanic blacks and $65.4 \%$ among those over 60 years of age. [10] Prevalence of Hypertension 33\% was found in Korea, [11] 24\% in china [12] and 26\% among age 20-35 years in Portugal. [13] Lower prevalence 4.6/1000 population was found among "Oraon" population. [14] These differences are due to different level of blood pressure, study age groups.

To interpret these results some points need to take into consideration that this study was carried out at combined military hospital Dhaka where only 30\% of the military personnel $(n=245)$ did not attend the outpatient clinic for data collection. However, we believe that this fact does not affect results interpretation, as the sample was composed of military personnel from all ranks, who developed the different activities. For admission in Bangladesh Army, the individuals are required to qualify some characteristics like certain limit of height and weight, absence of physical or mental disabilities.

Body mass index (BMI) has a strong predictor of hypertension. Raised BMI increase the possibilities of 
Hypertension, on the other hand regular physical exercise protect from hypertension. In this study most of the hypertensive individuals are taking their meal from barak, food source of sainik barak may have some influence on early onset hypertension but needs further study. Hypertensive retinopathy is a chronic process but already 5\% of respondents developed early stages of hypertensive changes in fundus. Raised level of LDL and Triglyceride also found among hypertensive respondents. Frequency of hypertension also found more with the increased level of mental stress. So, there are some modifiable risk factors for development of early onset hypertension among military personnel, but further study required regarding this matter.

\section{CONCLUSION}

Hypertension is one of the leading causes of death in the world. [15] Hypertension affects many organs of the body like brain, heart, kidney, eye etc. Management of Hypertension and its complication not only influence on individual health but also influence on economic development of a country by influencing on national budget and human disability. The effective management of hypertension is therefore a primary health care objective. Hypertension is an emerging health problem in Bangladesh. [16] Despite standards for weight and fitness, military personnel are not immune to hypertension and $16.3 \%$ of military service personnel were found hypertensive after 10 years of services.

\section{REFERENCES}

[1] G. R, "Meta-analysis of prevalence of hypertension in India.," Indian Heart Journal, pp. 49(1):43-48, 1997.

[2] R. A. B.Singh, "Diet, central obesity and prevalence of hypertension in the urban population of South India," International Journal of Cardiology, pp. 183-191, 1995.

[3] B. S. G. H. Nissinen A, "Hypertension in developing countries," Europe PMC, pp. 41(3-4):141-154, 1988.

[4] R. B. S. A. K. R. K. B. S. S. DJanusiAPostiglionejMahmoodMoshirik, "Prevalence and risk factors of hypertension and age-specific blood pressures in five cities: A study of Indian women," International Journal of Cardiology, pp. 165-173, 1998.

[5] R. S. R. V. N. M. M. S. C. M. Singh RB1, "Blood pressure trends, plasma insulin levels and risk factors in rural and urban elderly populations of north India," Coronary Artery Disease, pp. 8(7):463468, 1997.

[6] Z. M. U. K. P. Hemna Siddiqui ( Departments of Family Medicine, "Risk factors assessment for hypertension in a squatter settlement of Karachi," Canvas Logo, pp. 0030-9982, 2005.

[7] S. G. A. D. M. B. C. M. S. K. \&. B. G. P.R. Deshmukh, "Relationship of anthropometric indicators with blood pressure," Indian J Med, pp. 657-664, 2006.

[8] C. C. R.-G. \&. L. A. Aday, "Prevalence of and Risk Factors for Hypertension in a Rural Area of the Philippines," Journal of Community Health, p. 389-399, 2000.

[9] W. e. committe, "Hypertension control," WHO Library cateloguing, geneva, 1996.

[10] M. M. Ihab Hajjar and M. Theodore A. Kotchen, "Trends in Prevalence, Awareness, Treatment, and Control of Hypertension in the United States, 1988-2000," JAMA, pp. 199-206, 2003.

[11] I. Jo, Y. Ahn, J. Lee, K. R. Shin, H. K. Lee and C. Shin, "Prevalence, awareness, treatment, control and risk factors of hypertension in Korea: the Ansan study," journal of hypertension, pp. 1523-1532, 2001.
[12] W. Y. Z. L. L. Y. Y. J. Z. B. Wang ZW1, "Trends in prevalence, awareness, treatment and control of hypertension in middle-aged Chinese population," Co-Operative Research Group of the Study on Trends of Cardiovascular Diseases in China And Preventive Strategy for the 21st Century, pp. 407-411, 2004.

[13] M. E. Macedo, M. J. Lima, A. O. Silva, P. Alcantara, V. Ramalhinho and J. Carmona, "Prevalence, awareness, treatment and control of hypertension in Portugal: the PAP study," Journal of Hypertension, pp. 1661-1666, 2005.

[14] S. K. Dash SC1, "Blood pressure profile, urinary sodium and body weight in the 'Oraon' rural and urban tribal community.," The Journal of the Association of Physicians of India, pp. 42(11):878-880, 1994.

[15] M. B. M. S. a. K. S. R. M. D. David J. Hunter, "Noncommunicable Diseases," GLOBAL HEALTH, pp. 1336-1343, 2013.

[16] H. Z. M. A. Shahriar I, "Patterns of Antihypertensive Drugs Used in Two Postgraduate Institutions.," Journal of Dhaka National Medical college and Hospital, pp. 41-42, 2008.

[17] R. R. Tiwari, "Hypertension and Epidemiological Factors among," Indian Journal of Public Health, pp. 144-146, 2008.

[18] G. N. Chadha SL, "Epidemiological study of coronary heart disease in Gujaratis in Delhi (India).," The Indian Journal of Medical Research, , pp. 96:115-121, 1992. 